\title{
Clinical Approach to Manage Gastrointestinal Bleeding with a Left Ventricular Assist Device (LVAD)
}

\author{
Irfan Ahsan $^{1}$, Aniqa Faraz ${ }^{2}$, Asif Mehmood ${ }^{3,4}$, Waqas Ullah ${ }^{4}$, Ali R. Ghani ${ }^{5}$ \\ 1. Internal Medicine, Geisinger Health System, Danville, USA 2. Internal Medicine, University of Buffalo, Buffalo, USA \\ 3. Internal Medicine, Geisinger Medical Center, Danville, USA 4. Internal Medicine, Abington Hospital - Jefferson \\ Health, Abington, USA 5. Cardiovascular Medicine, Saint Louis University, Saint Louis, USA
}

Corresponding author: Irfan Ahsan, iahsan@geisinger.edu

\begin{abstract}
Left ventricular assist devices (LVADs) are an exceedingly important form of mechanical support for patients with end-stage heart failure. LVADs can be utilized both as a bridge to cardiac transplant and also as a definitive treatment. However, a few complications are associated with LVAD placement, the most common and cumbersome of which is gastrointestinal (GI) bleeding with an incidence of about $30 \%$. These bleeding events often require transfusion therapy, but they are rarely fatal.
\end{abstract}

The etiologies of GI bleeding following LVAD are multifactorial and include unstable hemodynamics, an acquired von Willebrand factor (vWf) deficiency, impaired platelet aggregation, and activation of fibrinolytic systems. The treatment of choice in LVAD implantation-associated GI bleeding is endoscopy, which plays a vital role in both its diagnosis and management. Even so, its effectiveness in controlling post-LVAD implantation GI bleeding is still poorly ascertained. In this article, we will review the use of medication and alterations in the LVAD setting to prevent the occurrence of GI bleeding, as well as the findings of previously reported literature on LVAD implantation-associated GI bleeding.

Categories: Cardiology, Gastroenterology

Keywords: gastrointestinal bleeding, end-stage heart failure, left ventricular assist device (lvad)

\section{Introduction And Background}

Heart failure is a progressively debilitating and chronic disease afflicting approximately 5.8 million adults in the United States (US) [1]. It has been singled out as an epidemic and is a progressive, debilitating health care problem with significant mortality and morbidity, especially in patients above 65 years [2]. It carries a mortality of around $50 \%$ in the next five years, thereby surpassing many malignancies [3]. The continuous rise in the number of patients with progressive heart failure has been due to prolonged survival from improved cardiovascular interventions and advancements in medical therapy. The mainstay of management has mostly been medical over the past years, but patients who are considered refractory to medical therapy are put on waiting lists for heart transplantation. A heart transplant is the gold standard treatment for endstage heart failure; however, due to the limited availability of donor hearts, it is difficult to perform a transplant on every patient with end-stage heart failure. According to statistics, only 2,000 transplants are performed every year as a consequence of the donor shortage throughout the United States [4]. Once readmissions for heart failure exacerbations seem to recur, the prognosis tends to get worse [5-6]. The firstever mechanical circulatory device was implanted in 1963 by DeBakey in a patient who had cardiac arrest after aortic valve replacement [7]. In the 1980s, ventricular assist devices (VADs) were first approved by the Food and Drug Administration (FDA) to be used as a bridge to transplant [8]. Since the Randomized Evaluation of Mechanical Assistance for the Treatment of Congestive Heart Failure (REMATCH) trial in 2001, left ventricular assist devices (LVADs) are not only used as a bridge to transplant but also as a destination therapy for myocardial recovery among those who are not suitable candidates or for whom a timely transplant is not available [9-10]. LVAD-related complications occur in $60 \%$ of patients within six months, and by two years, the majority of patients have experienced a major adverse event [11].

Gastrointestinal (GI) bleeding is a major cause of morbidity after LVAD implantation and its incidence has increased from 5\% in 2005 to around 10\% in 2010 [12]. Traditionally started as a pulsatile flow (PF) LVADs (which had a larger size and were more prone to thrombosis), continuous flow (CF) LVADs have become the standard of care with over three times the increased risk of GI bleeding. This ultimately leads to an increase in the length of hospital stay, the cost burden on health care resources, and hospital readmission rates [10, 12]. The purpose of this article is to review the literature focusing on the diagnosis and management of gastrointestinal bleeding in patients with LVAD from an internist's point of view.

\section{Clinical presentation and risk factors}

Patients with LVAD-associated GI hemorrhage most commonly present with hematemesis, melena, and rectal bleeding. Some patients may be otherwise asymptomatic, while others may complain of fatigue, 
weakness, or dizziness. Hemodynamic instability may occur in a few cases. These symptoms often develop five months subsequent to LVAD placement but may also occur immediately or long after LVAD placement. Laboratory analysis may frequently show anemia, a raised international normalized ratio (INR), and a decrease in the platelet count.

GI bleeding following LVAD placement has various risk factors and is most commonly seen in elderly males. Other risk factors include a previous history of pre-LVAD GI bleed, antiplatelet and vitamin K antagonist use, right ventricular dysfunction, and post-LVAD ejection fraction > 30\% [13].

\section{Pathophysiology and etiology}

The pathophysiology of GI bleeding secondary to LVAD implantation is still controversial. One of the mechanisms to explain the increased risk of bleeding is endothelial dysfunction from non-pulsatile blood flow, which was more commonly observed in patients supported by CF-LVADs than PF-LVADs. It was discovered that there was a loss of physiologic pulsatility which is associated with the normal cardiac contraction cycle in patients treated with CF-LVADs, consequently causing a narrowed arterial pulse pressure and leading to a decrease in the aortic valve opening [14].

Another mechanism proposed is acquired von Willebrand disease from increased degradation of the von Willebrand factor (vWF) impaired platelet aggregation, leading to increased bleeding [15-16]. Acquired vWD was first described in 2003 to explain arteriovenous malformations (AVMs) in severe aortic stenosis (Heyde's syndrome). This pathophysiology is believed to be somewhat similar to AVM bleeds in CF-LVADs [17]. It is hypothesized that vWF has an important role in the regulation of angiogenesis [18]. In 2011, a study published by Starke et al. recruited mice as subjects and demonstrated that a lack of vWF in the WeibelPalade bodies of endothelial cells led to increased angiogenesis and neovascularization in those mice subjects [19]. Therefore, it can be concluded that a deficiency of vWF leads to an increased number of endothelial cells and cytokines which leads to an increased rate of angiogenesis and subsequently to the development of arteriovenous malformations.

Some authors also attribute GI bleeding to the decreased amount of high-molecular-weight multimers due to the mechanical forces of the LVAD device, leading to ineffective thrombosis and platelet aggregation [20]. This was shown in a study performed by Hayes et al. in which 37 patients had undergone CF-LVAD implantation [21].

The use of both warfarin and aspirin has also been implicated as the cause of increased bleeding in patients with CF-LVAD as compared to aspirin only in PF-LVAD patients. These patients required anticoagulation because of the increased risk of pump thrombosis. However, some studies have shown that a decrease in INR (1.5 - 2.5 range) could be achieved without posing a risk for thromboembolism [22]. Furthermore, a few studies have suggested that there might be a genetic predisposition to the development of bleeding tendencies and thromboembolism in LVAD patients. It is suggested that, in patients who are sensitive to warfarin, there may be rare polymorphisms in CYP2C9 and vitamin K epoxide reductase complexes, leading to bleeding and thromboembolism [23]. However, this hypothesis does necessitate further studies for its justification.

In observational studies, CF-LVAD was associated with a 10-fold increased risk of Gl bleeding as compared to PF-LVAD [15]. Similarly, in a cohort of 112 patients, 39\% of the patients had GI bleeding, and endoscopy was able to identify the bleeding source in $57 \%$ of the patients [16].

Other mechanisms that could lead to GI bleeding in patients of LVAD include impaired platelet aggregation, activation of fibrinolytic systems, and nonsteroidal anti-inflammatory drug (NSAID) use. It was observed that the majority of LVAD recipients had impaired platelet aggregation which normalized after a heart transplant [24]. This impairment in platelet function occurs due to an increased sensitivity of the platelets to shear stress [25].

Patients undergoing LVAD implantation have activation of fibrinolytic systems, especially elderly patients with end-stage cardiac failure. The cause of this increased fibrinolysis is most likely a result of a preexisting state of inflammation [26]. It has been observed that the majority of post-LVAD placement bleeding episodes occur during the first year [27] and that d-dimer and fibrinogen levels peak at one month and return to normal a year after of LVAD implantation [28]. The pathophysiology of GI bleeding has been discussed in Figure 1. 


\section{Cureus}

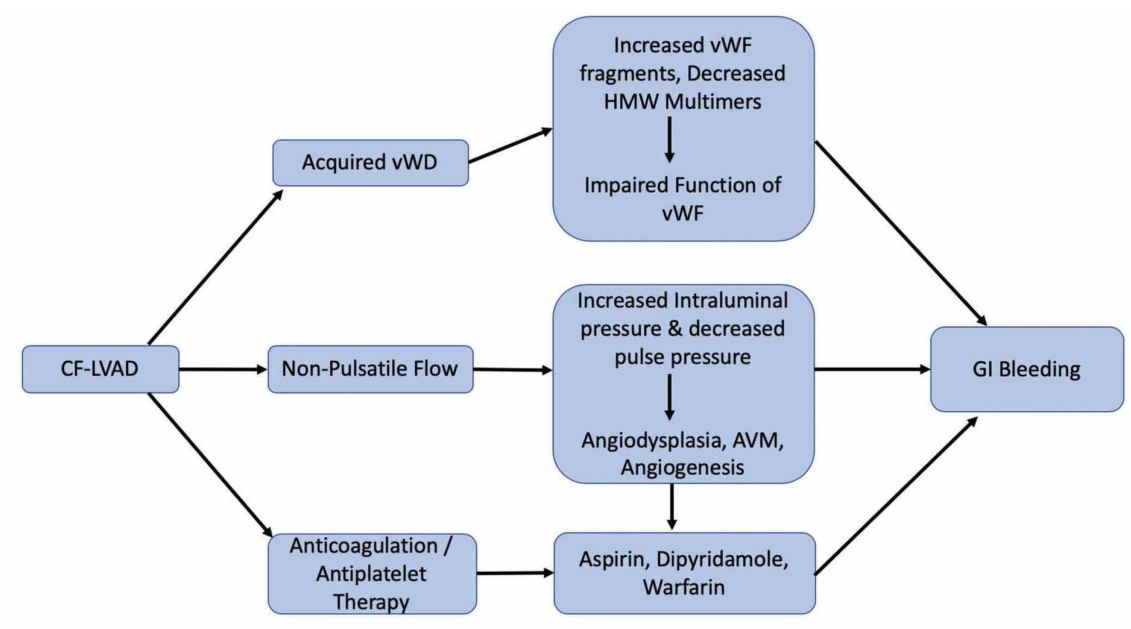

FIGURE 1: Algorithm on the pathophysiology of gastrointestinal bleeding

AVM: arteriovenous malformation; CF-LVAD: continuous-flow left ventricular assist device; GI: gastrointestinal; HMW: high-molecular-weight; vWD: von Willebrand disease; vWF: Von Willebrand factor

The upper GI tract, lower GI tract, and small bowel account for 48\%, 22\%, and 15\% of GI bleeding episodes, respectively [29]. The majority of bleeding episodes in LVAD patients are secondary to underlying AVMs and they are usually not life-threatening. If the bleeding is brisk, it is less likely related to an AVM and the patient needs an emergent scope to rule out other etiologies of gastrointestinal bleeding. The majority of bleeding episodes do get resolved in an average of four days and usually require an average of four packed red blood cell units [30-32]. Table 1 discusses the various studies which highlighted the cause of GI bleeding. 


\section{Cureus}

\begin{tabular}{|c|c|c|c|c|c|c|c|c|c|c|c|c|c|}
\hline $\begin{array}{l}\text { S. } \\
\text { No }\end{array}$ & Author & $\begin{array}{l}\text { Year } \\
\text { of } \\
\text { Study }\end{array}$ & $\begin{array}{l}\text { Details of } \\
\text { LVAD } \\
\text { placement }\end{array}$ & $\begin{array}{l}\text { Total } \\
\text { Incidence }\end{array}$ & Gastritis & $\begin{array}{l}\text { Gastric } \\
\text { Ulcer }\end{array}$ & AVM & Diverticulitis & Colitis & $\begin{array}{l}\text { Colonic } \\
\text { Polyp }\end{array}$ & $\begin{array}{l}\text { Colonic } \\
\text { Ulcer }\end{array}$ & Other & Unknown \\
\hline 1 & $\begin{array}{l}\text { Hayes et } \\
\text { al. [21] }\end{array}$ & 2010 & $\begin{array}{l}\text { aVentrAssist } \\
\text { TM : } 20 \%, \\
\text { bJarvik } \\
2000^{\circledR}: 40 \%, \\
{ }^{C} \text { HeartWare }{ }^{\circledR} \text { : } \\
40 \%\end{array}$ & $13.9 \%$ & & & $60.0 \%$ & & & & $20.0 \%$ & & $20.0 \%$ \\
\hline 2 & $\begin{array}{l}\text { Demirozu } \\
\text { et al. [13] }\end{array}$ & 2011 & $\begin{array}{l}\text { Continuous- } \\
\text { flow } \\
\text { dHeartMate II } \\
\text { TM LVAD }\end{array}$ & $19.0 \%$ & $31.3 \%$ & & $31.3 \%$ & $18.8 \%$ & $3.2 \%$ & $3.2 \%$ & & $12.5 \%$ & \\
\hline 3 & $\begin{array}{l}\text { Aggarwal } \\
\text { et al. [33] }\end{array}$ & 2012 & $\begin{array}{l}\text { Continuous- } \\
\text { flow } \\
\text { dHeartMate II } \\
\text { TM LVAD }\end{array}$ & $22.8 \%$ & $30.4 \%$ & $8.7 \%$ & $21.7 \%$ & & & $4.3 \%$ & $13.0 \%$ & $13.0 \%$ & $8.7 \%$ \\
\hline 4 & $\begin{array}{l}\text { Kushnir } \\
\text { et al. [34] }\end{array}$ & 2012 & $\begin{array}{l}\text { Pulsatile } \\
\text { eHM-XVE: } \\
27.3 \% ; \\
\text { continuous- } \\
\text { flow } \\
{ }^{{ }} \text {HeartMate II } \\
{ }^{\mathrm{TM}}: 72.7 \%\end{array}$ & $34.8 \%$ & & $28.2 \%$ & $30.8 \%$ & & $5.1 \%$ & $5.1 \%$ & & & $30.8 \%$ \\
\hline 5 & $\begin{array}{l}\text { Wever- } \\
\text { Pinzon et } \\
\text { al. [11] }\end{array}$ & 2013 & $\begin{array}{l}\text { Continuous- } \\
\text { flow } \\
\text { dHeartMate II } \\
\text { TM LVAD }\end{array}$ & $17.2 \%$ & $8.7 \%$ & & $61.0 \%$ & $8.7 \%$ & $4.3 \%$ & $8.7 \%$ & & $8.7 \%$ & \\
\hline
\end{tabular}

\section{TABLE 1: Summary of All Studies Identifying the Source of GI Bleeding}

${ }^{\mathrm{a}}$ VentrAssist ${ }^{\mathrm{TM}}$ (Ventracor Ltd., Sydney, Australia)

bJarvik $2000 \circledast$ (Jarvik Heart, Inc., New York, NY)

${ }^{C}$ HeartWare HVAD $®$ (HeartWare, Framingham, MA)

${ }^{\mathrm{d}}$ HeartMate $\mathrm{II}^{\mathrm{TM}}$ LAVD (Thoratec Corp., Pleasanton, CA)

eHeartMate $₫$ XVE (Thoratec Corp., Pleasanton, CA)

AVM: arteriovenous malformation; HM-XVE: HeartMate ${ }^{\mathrm{TM}}$ XVE; LVAD: left ventricular assist device

\section{Review}

GI bleeding is a dreaded complication of LVAD implantation which can potentially lead to hemodynamic instability and eventually life-threatening hemorrhagic shock. The management of post-LVAD GI bleeding requires urgent evaluation with a multidisciplinary approach. Managing the anticoagulation in these patients can be challenging and comes at the risk of pump thrombosis versus life-threatening hemorrhage. The role of a clinician is important in evaluating such patients who are at high risk of lifethreatening bleeding. Furthermore, the risk stratification of these patients who are at risk of recurrence and readmissions is required. In patients with no obvious bleeding but a significant drop in hemoglobin, LVAD thrombosis or hemolysis is a crucial differential to be considered and requires urgent intervention. High serum lactate dehydrogenase (LDH) can play a vital role in differentiating hemolysis from bleeding [35]. The management strategy relies on the patient hemodynamics, severity of bleeding, coexisting coronary artery disease, the availability of state-of-the-art therapeutic options, and other indications of anticoagulation 
(e.g., the history of the thromboembolic phenomenon). Initial resuscitation by intravenous crystalloids and blood products, followed by noninvasive diagnostic modalities (e.g., computed tomography angiography) and invasive techniques (e.g., esophagogastroduodenoscopy, video capsule endoscopy, tagged red blood cell (RBC) scan, mesenteric angiogram, single balloon enteroscopy, deep balloon-assisted enteroscopy, and colonoscopy) are the major tools in the clinical approach.

\section{Management}

Antithrombotics are the cornerstone therapy in the outpatient management of LVAD. In addition to aspirin, warfarin is the anticoagulant of choice, while direct thrombin inhibitors (e.g., dabigatran) have failed to ascertain their usefulness in these patients [36]. Dabigatran was studied in a prospective randomized study in which 30 patients were randomized to either dabigatran or phenprocoumon (vitamin K antagonist). This trial was prematurely discontinued due to the increased thromboembolic phenomenon observed in half of the patients (four out of eight) receiving dabigatran [36]. On warfarin therapy, the target INR is $2.0-3.0$ in LVAD patients [30]. LVAD patients with previous deep venous thrombosis, pulmonary embolism, and inherited thrombophilia have a higher INR goal (2.5 - 3.5) [31]. Similarly, patients with atrial fibrillation and/or history of stroke have an INR goal of 2.5 - 3.0. Higher INR goals require repetitive testing and are associated with bleeding and thromboembolic complications with an event rate of 0.06 per patient-year for GI bleeding [31]. At a follow-up of one year, only one-third of patients are without bleeding or thromboembolic complications. At the time of bleeding, the average INR was found to be approximately 3.3 [32]. Ultimately, the management relies upon the individual clinician and the patient [37].

LVAD patients with gastrointestinal hemorrhage require a multidisciplinary and comprehensive approach. A detailed history and examination should be performed, along with initial assessment and hemodynamic resuscitation. As mentioned earlier, NSAID use is a predisposing factor to the development of GI bleeding; hence, their use should be enquired in the patient history. Physical examination should include the assessment of LVAD function by the cardiology team and a gastroenterology consult should be taken in the Emergency Department, after which intensive care admission should be assessed. Investigations should include a complete blood count, metabolic and hepatic panels, and should also focus on INR, fibrinogen, and d-dimer levels. However, the decision of withholding antiplatelet and anticoagulation therapy needs to be discussed with the Cardiology Department, keeping in mind the risk of thrombosis in the immediate future. A schematic outline of the management approach has been summarized in Figure 2.

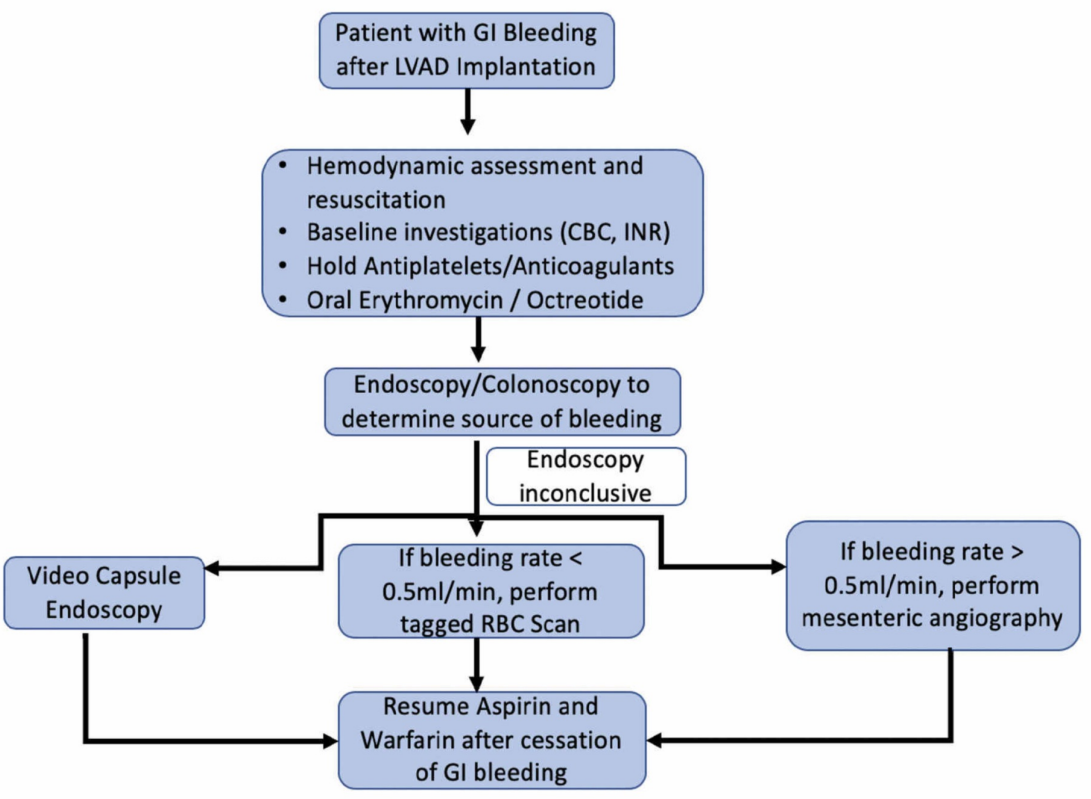

FIGURE 2: Flowsheet outlining the management approach to GI bleeding in patients with LVAD placements

CBC: complete blood count; GI: gastrointestinal; INR: international normalized ratio; LVAD: left ventricular assist devices; RBC: red blood cells

Mild to Moderate Bleeding

The majority of gastrointestinal bleeds in LVAD patients are not life-threatening but are a cause of increased 
morbidity and recurrent hospitalizations. For patients with mild to moderate bleeding, the approach should be to stop the anticoagulation and perform an endoscopy. Endoscopy is an extremely useful modality for the diagnosis and treatment of GI bleeding, but it can yield false-negative results by stopping the occult bleed. Moreover, endoscopy is non-diagnostic in over two-thirds of the patients [16]. After the source of bleeding is found and treated accordingly, aspirin should be withheld and warfarin should be restarted with a lower INR goal. Maintaining a balance between bleeding and thromboembolism with close outpatient follow-up is a decision that rests with the physician and patients, based on individualized risk factors [37]. Holding anticoagulation for two to four weeks after GI bleeding may lead to an increased risk of thromboembolic events. In these patients who present with hematochezia or an occult bleed, colonoscopy after bowel preparation is used to diagnose the cause of GI bleeding. In the case of a suspected small intestinal angiodysplastic lesion, a push enteroscopy is required to evaluate the proximal jejunum. About $29 \%-90 \%$ of LVAD patients who had GI hemorrhage benefited from push enteroscopy, thereby decreasing their risk of future rebleeding and readmission [16]. If colonoscopy fails to disclose the etiology, then performing an esophagogastroduodenoscopy (EGD) is the next best step. According to the American College of Gastroenterology guidelines, the patients with an upper GI bleed should undergo endoscopy within 24 hours, following resuscitative efforts to optimize hemodynamic parameters [30]. When both these measures fail, video capsule endoscopy should be performed as it has been shown to have a high bleeding detection rate (about $40 \%$ of cases, mostly confined to the proximal small intestine) [38]. However, video capsule endoscopy is not therapeutic and may result in an increased hospital stay of the patient. In an active overt GI bleed, a tagged RBC scan and angiography are the other modalities to consider. The bleeding rate needs to be determined, i.e, if the bleeding rate is $0.1-0.5 \mathrm{ml} / \mathrm{min}$, then a tagged $\mathrm{RBC}$ scan can be appropriate; however, for $>0.5 \mathrm{ml} / \mathrm{min}$ bleeding, angiography with suspected possible angiographic intervention is done [39].

Severe Bleeding

In patients who are hemodynamically unstable or have profuse bleeding, immediate resuscitative efforts to maintain hemodynamic stability and prophylactic intubation should be performed. All anticoagulant and antiplatelet drugs should be stopped and fluid resuscitation should be initiated. Immediate consults from gastroenterologists or concerned specialists should be obtained. Vitamin K is given in severe cases of bleeding when extended time is expected to be off anticoagulation. However, once the patient is stabilized, warfarin should be restarted immediately. Restarting warfarin anticoagulation can prove to be difficult due to excess vitamin $\mathrm{K}$ levels in the blood. The decision to reverse anticoagulation should be made after involving the LVAD team (heart-failure specialist and cardiothoracic surgeon) and reviewing patient parameters like PT/INR (prothrombin time/international normalized ratio) and hemodynamic status as to give vitamin $\mathrm{K}$ or fresh frozen plasma.

\section{Controversial Medical Therapies}

Several medical therapies have been studied which have not yet been inculcated into clinical practice. Oral erythromycin (250 mg) 30 minutes before endoscopy may improve diagnostic yield by removing clots [40]. The role of nasogastric lavage has been controversial. In previous studies, a positive lavage was useful in finding the high-risk lesion and it has been associated with the earlier endoscopy, but it was not associated with a change in clinical outcomes [41]. The somatostatin analog, octreotide, is an effective therapy to control GI bleeding, especially when due to angiodysplasia [42]. By splanchnic vasoconstriction, platelet aggregation, and angiogenesis inhibition, it leads to the reduction in the requirement of blood units and hospital admissions after LVAD implantation-associated GI bleeding. A retrospective review performed by Hayes et al. successfully treated five patients with GI bleeding using octreotide, adrenaline infusion, and a reduction in pump flow [21]. However, a larger case series showed that octreotide did not have a noteworthy effect on the rate of recurrent GI bleeding. Thalidomide has also been used in various small studies because of its angiogenic properties [43]. Patients with LVAD have a high factor VIII and ristocetin cofactor activity due to inflammation; however, in patients with cardiac etiology, only $10 \%$ have responded to desmopressin [16]. A recent study by Fischer et al. demonstrated the use of vWF concentrate, devoid of factor VIII, in a CF-LVAD patient with severe GI bleeding. The use of vWF concentrate helped stabilize hemoglobin and effectively stopped bleeding without increasing the risk of thromboembolism [44]. The management of GI bleeding has been summarized in Figure 2. These studies warrant a need for further research in the management of GI bleeding secondary to LVAD placement, with emphasis on individual anticoagulant therapy. Table 2 discusses the incidence of GI bleeding after LVAD implantation in recent observational studies. 


\section{Cureus}

\begin{tabular}{|c|c|c|c|c|}
\hline $\begin{array}{l}\text { Study } \\
\text { Author }\end{array}$ & $\begin{array}{l}\text { Year of } \\
\text { Publication }\end{array}$ & Major Question & Major Outcome of The Study & Treatment \\
\hline $\begin{array}{l}\text { Aggarwal } \\
\text { et al. [33] }\end{array}$ & 2012 & $\begin{array}{l}\text { To identify incidence, } \\
\text { etiology, and management of } \\
\text { GI bleed in LVAD patients }\end{array}$ & $\begin{array}{l}\text { The incidence was found to be } 22.8 \% \text { in the destination } \\
\text { therapy population. Multiple factors are responsible for Gl } \\
\text { bleeding in LVAD patients }\end{array}$ & $\begin{array}{l}\text { Stopping anticoagulation } \\
\text { therapy, reduced the } \\
\text { speed of LVAD and } \\
\text { octreotide treatment }\end{array}$ \\
\hline $\begin{array}{l}\text { Akhter et } \\
\text { al. [45] }\end{array}$ & 2015 & $\begin{array}{l}\text { To find incidence and causes } \\
\text { of hospital readmissions after } \\
\text { LVAD implantation }\end{array}$ & $\begin{array}{l}\text { GI bleeding and LVAD-related infections were the major } \\
\text { causes of readmissions. These readmissions were found } \\
\text { to have no impact on long-term survival. }\end{array}$ & $\mathrm{N} / \mathrm{A}$ \\
\hline $\begin{array}{l}\text { French et } \\
\text { al. [46] }\end{array}$ & 2013 & $\begin{array}{l}\text { When is the highest rate of Gl } \\
\text { bleeding following LVAD } \\
\text { implantation? }\end{array}$ & $\begin{array}{l}\text { The highest hazard by GI bleeding was found to be early } \\
\text { post-implantation, stressing the importance of follow-up } \\
\text { immediately after implantation. }\end{array}$ & $\mathrm{N} / \mathrm{A}$ \\
\hline $\begin{array}{l}\text { Jabbar et } \\
\text { al. [47] }\end{array}$ & 2015 & $\begin{array}{l}\text { To identify the incidence, } \\
\text { recurrence, and predictors of } \\
\text { GI bleeding and impact of } \\
\text { endoscopy in LVAD patients. }\end{array}$ & $\begin{array}{l}\text { Gl bleeding is common, especially from the upper Gl } \\
\text { tract. An upper endoscopy can identify lesions in } 50 \% \text { of } \\
\text { patients. For management, a reduction in pump speed is } \\
\text { an effective strategy. }\end{array}$ & $\begin{array}{l}\text { Stopping } \\
\text { anticoagulation/antiplatelet } \\
\text { therapy; endoscopy }\end{array}$ \\
\hline $\begin{array}{l}\text { Yavar et } \\
\text { al. [48] }\end{array}$ & 2017 & $\begin{array}{l}\text { Sex-related bleeding } \\
\text { complications after CF-LVAD }\end{array}$ & $\begin{array}{l}\text { Females had a } 60 \% \text { higher hazard of bleeding than males } \\
\text { with significant morbidity encountered from mucosa } \\
\text { (including vaginal) bleeding. Future large device studies } \\
\text { should be inclusive of sex-specific outcomes. }\end{array}$ & $\begin{array}{l}\text { Admission and blood } \\
\text { transfusion }\end{array}$ \\
\hline LVAD: & 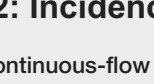 & lee $e^{2}$ & inal; LVAD: left & ot available \\
\hline
\end{tabular}

\section{Conclusions}

With the increased longevity of heart failure patients, LVAD has become the standard of care in contemporary practice as a bridge to transplant or destination therapy. Due to the paucity of data, postLVAD bleeding poses a challenge to the anticoagulation of such patients who are at high risk of pump thrombosis. A multidisciplinary team-based approach is vital in the prompt diagnosis and treatment of GI bleeding in LVAD patients. Further studies are required to define the predictors of GI bleeding so that highrisk patients can be risk-stratified to decrease morbidity and mortality.

\section{Additional Information \\ Disclosures}

Conflicts of interest: In compliance with the ICMJE uniform disclosure form, all authors declare the following: Payment/services info: All authors have declared that no financial support was received from any organization for the submitted work. Financial relationships: All authors have declared that they have no financial relationships at present or within the previous three years with any organizations that might have an interest in the submitted work. Other relationships: All authors have declared that there are no other relationships or activities that could appear to have influenced the submitted work.

\section{References}

1. Bui AL, Horwich TB, Fonarow GC: Epidemiology and risk profile of heart failure . Nat Rev Cardiol. 2011, 8:30-41. 10.1038/nrcardio.2010.165

2. Roger VL: Epidemiology of heart failure. Circ Res. 2013, 113:646-59. 10.1161/CIRCRESAHA.113.300268

3. Szema A, McLarty A, Skopicki H, Bloom M, Jermyn R: Heart failure: an exploration of recent advances in research and treatment (A). Clin Med Insights Cardiol. 2015, 9:53-56. 10.4137/CMC.S32652

4. McLarty A: Mechanical circulatory support and the role of LVADs in heart failure therapy . Clin Med Insights Cardiol. 2015, 9:1-5. 10.4137/CMC.s19694

5. Goldberg RJ, Ciampa J, Lessard D, Meyer TE, Spencer FA: Long-term survival after heart failure: a contemporary population-based perspective. Arch Intern Med. 2007, 167:490-96. 10.1001/archinte.167.5.490

6. Levy D, Kenchaiah S, Larson MG, et al.: Long-term trends in the incidence of and survival with heart failure . N Engl J Med. 2002, 347:1397-402. 10.1056/NEJMoa020265

7. DeBakey ME, Liotta D, Hall WC: Left-heart bypass using an implantable blood pump . Mechanical Devices to Assist the Failing Heart. National Academy of Science, Washington, DC; 1966. Publication 1283:223-39.

8. Jessup M, Núñez-Gil IJ: Heart failure and mechanical circulatory assist devices: new answers to old questions. Rev Esp Cardiol. 2008, 61:1231-35. 10.1016/S1885-5857(09)60048-7 
9. Rose EA, Moskowitz AJ, Packer M, et al.: The REMATCH trial: rationale, design, and end points . Ann Thorac Surg. 1999, 67:723-30. 10.1016/s0003-4975(99)00042-9

10. Loor G, Gonzalez-Stawinski G: Pulsatile vs. continuous flow in ventricular assist device therapy . Best Pract Res Clin Anaesthesiol. 2012, 26:105-15. 10.1016/j.bpa.2012.03.004

11. Wever-Pinzon O, Drakos SG, Kfoury AG, et al.: Morbidity and mortality in heart transplant candidates supported with mechanical circulatory support: is reappraisal of the current United Network for organ sharing thoracic organ allocation policy justified?. Circulation. 2013, 127:452-62.

10.1161/CIRCULATIONAHA.112.100123

12. Joy PS, Kumar G, Guddati AK, Bhama JK, Cadaret LM: Risk factors and outcomes of gastrointestinal bleeding in left ventricular assist device recipients. Am J Cardiol. 2016, 117:240-44. 10.1016/j.amjcard.2015.10.041

13. Demirozu ZT, Radovancevic R, Hochman LF, et al.: Arteriovenous malformation and gastrointestinal bleeding in patients with the HeartMate II left ventricular assist device. J Heart Lung Transplant. 2011, 30:849-53. 10.1016/j.healun.2011.03.008

14. Letsou GV, Shah N, Gregoric ID, Myers TJ, Delgado R, Frazier OH: Gastrointestinal bleeding from arteriovenous malformations in patients supported by the Jarvik 2000 axial-flow left ventricular assist device. J Heart Lung Transplant. 2005, 24:105-109. 10.1016/j.healun.2003.10.018

15. Crow S, Chen D, Milano C, et al.: Acquired von Willebrand syndrome in continuous-flow ventricular assist device recipients. Ann Thorac Surg. 2010, 90:1263-69. 10.1016/j.athoracsur.2010.04.099

16. Gurvits GE, Fradkov E: Bleeding with the artificial heart: gastrointestinal hemorrhage in CF-LVAD patients . World J Gastroenterol. 2017, 23:3945-53. 10.3748/wjg.v23.i22.3945

17. Vincentelli A, Susen S, Le Tourneau T, et al.: Acquired von Willebrand syndrome in aortic stenosis. N Engl J Med. 2003, 349:343-49. 10.1056/NEJMoa022831

18. Franchini M, Mannucci PM: Gastrointestinal angiodysplasia and bleeding in von Willebrand disease . Thromb Haemost. 2014, 112:427-31. 10.1160/TH13-11-0952

19. Starke RD, Ferraro F, Paschalaki KE, et al.: Endothelial von Willebrand factor regulates angiogenesis. Blood. 2011, 117:1071-80. 10.1182/blood-2010-01-264507

20. Uriel N, Pak S, Jorde UP, et al.: Acquired von Willebrand syndrome after continuous-flow mechanical device support contributes to a high prevalence of bleeding during long-term support and at the time of transplantation. J Am Coll Cardiol. 2010, 56:1207-13. 10.1016/j.jacc.2010.05.016

21. Hayes HM, Dembo LG, Larbalestier R, O'Driscoll G: Management options to treat gastrointestinal bleeding in patients supported on rotary left ventricular assist devices: a single-center experience. Artif Organs. 2010, 34:703-706. 10.1111/j.1525-1594.2010.01084.x

22. Harris LA, Hansel SL, Rajan E, et al.: Capsule endoscopy in patients with implantable electromedical devices is safe. Gastroenterol Res Pract. 2013, 2013:959234. 10.1155/2013/959234

23. Cushing K, Kushnir V: Gastrointestinal bleeding following LVAD placement from top to bottom . Dig Dis Sci. 2016, 61:1440-47. 10.1007/s10620-016-4123-4

24. Stulak JM, Lee D, Haft JW, et al.: Gastrointestinal bleeding and subsequent risk of thromboembolic events during support with a left ventricular assist device. J Heart Lung Transplant. 2014, 33:60-64. 10.1016/j.healun.2013.07.020

25. Coutance G, Saplacan V, Belin A, Repessé Y, Buklas D, Massetti M: Octreotide for recurrent intestinal bleeding due to ventricular assist device. Asian Cardiovasc Thorac Ann. 2014, 22:350-52. 10.1177/0218492312474902

26. Sarosiek K, Bogar L, Conn MI, O'Hare B, Hirose H, Cavarocchi NC: An old problem with a new therapy: gastrointestinal bleeding in ventricular assist device patients and deep overtube-assisted enteroscopy. ASAIO J. 2013, 59:384-89. 10.1097/MAT.0b013e318299fcd3

27. Barbara DW, Olsen DA, Pulido JN, Boilson BA, Bruining DH, Stulak JM, Mauermann WJ: Periprocedural management of 172 gastrointestinal endoscopies in patients with left ventricular assist devices. ASAIO J. 2015, 61:670-75. 10.1097/MAT.0000000000000269

28. Slaughter MS, Sobieski MA, Gallagher C, Graham J, Brandise J, Stein R: Fibrinolytic activation during longterm support with the HeartMate II left ventricular assist device. ASAIO J. 2008, 54:115-19. 10.1097/MAT.0b013e318161a987

29. Draper KV, Huang RJ, Gerson LB: GI bleeding in patients with continuous-flow left ventricular assist devices: a systematic review and meta-analysis. Gastrointest Endosc. 2014, 80:435-446.e1. 10.1016/j.gie.2014.03.040

30. Rossi M, Serraino GF, Jiritano F, Renzulli A: What is the optimal anticoagulation in patients with a left ventricular assist device?. Interact Cardiovasc Thorac Surg. 2012, 15:733-40. 10.1093/icvts/ivs297

31. Nassif ME, LaRue SJ, Raymer DS, Novak E, Vader JM, Ewald GA, Gage BF: Relationship between anticoagulation intensity and thrombotic or bleeding outcomes among outpatients with continuous-flow left ventricular assist devices. Circ Heart Fail. 2016, 9:e002680. 10.1161/CIRCHEARTFAILURE.115.002680

32. Baumann Kreuziger LM, Kim B, Wieselthaler GM: Antithrombotic therapy for left ventricular assist devices in adults: a systematic review. J Thromb Haemost. 2015, 13:946-55. 10.1111/jth.12948

33. Aggarwal A, Pant R, Kumar S, et al.: Incidence and management of gastrointestinal bleeding with continuous flow assist devices. Ann Thorac Surg. 2012, 93:1534-40. 10.1016/j.athoracsur.2012.02.035

34. Kushnir VM, Sharma S, Ewald GA, et al.: Evaluation of GI bleeding after implantation of left ventricular assist device. Gastrointest Endosc. 2012, 75:973-79. 10.1016/j.gie.2011.12.014

35. Tchantchaleishvili V, Sagebin F, Ross RE, Hallinan W, Schwarz KQ, Massey HT: Evaluation and treatment of pump thrombosis and hemolysis. Ann Cardiothorac Surg. 2014, 3:490-95. 10.3978/j.issn.2225319X.2014.09.01

36. Andreas M, Moayedifar R, Wieselthaler G, et al.: Increased thromboembolic events with dabigatran compared with vitamin K antagonism in left ventricular assist device patients: a randomized controlled pilot trial. Circ Heart Fail. 2017, 10:e003709. 10.1161/CIRCHEARTFAILURE.116.003709

37. Toeg H, Ruel M, Haddad H: Anticoagulation strategies for left ventricular assist devices . Curr Opin Cardiol. 2015, 30:192-96. 10.1097/HCO.0000000000000143

38. Amornsawadwattana S, Nassif M, Raymer D, LaRue S, Chen CH: Video capsule endoscopy in left ventricular 
assist device recipients with obscure gastrointestinal bleeding. World J Gastroenterol. 2016, 22:4559-66. 10.3748/wjg.v22.i18.4559

39. Guha A, Eshelbrenner CL, Richards DM, Monsour HP Jr: Gastrointestinal bleeding after continuous-flow left ventricular device implantation: review of pathophysiology and management. Methodist Debakey Cardiovasc J. 2015, 11:24-27.

40. Kim S, Muthusamy VR: Prophylactic erythromycin in acute upper gastrointestinal bleeding: moving forward in improving endoscopic efficacy. Saudi J Gastroenterol. 2013, 19:193-94. 10.4103/1319-3767.118109

41. Rockey DC, Ahn C, de Melo SW Jr: Randomized pragmatic trial of nasogastric tube placement in patients with upper gastrointestinal tract bleeding. J Investig Med. 2017, 65:759-64. 10.1136/jim-2016-000375

42. Szilagyi A, Ghali MP: Pharmacological therapy of vascular malformations of the gastrointestinal tract. Can J Gastroenterol. 2006, 20:171-78. 10.1155/2006/859435

43. Shurafa M, Kamboj G: Thalidomide for the treatment of bleeding angiodysplasias. Am J Gastroenterol. 2003, 98:221-22.

44. Fischer Q, Huisse MG, Voiriot G, et al.: Von Willebrand factor, a versatile player in gastrointestinal bleeding in left ventricular assist device recipients?. Transfusion. 2015, 55:51-54. 10.1111/trf.12788

45. Akhter SA, Badami A, Murray M, Kohmoto T, Lozonschi L, Osaki S, Lushaj EB: Hospital readmissions after continuous-flow left ventricular assist device implantation: incidence, causes, and cost analysis. Ann Thorac Surg. 2015, 100:884-89. 10.1016/j.athoracsur.2015.03.010

46. French JB, Pamboukian SV, Smallfield GB, et al.: 116: Gastrointestinal bleeding risk in patients with ventricular assist devices. J Heart Lung Transplant. 2012, 31:S47-S48. 10.1016/j.healun.2012.01.120

47. Jabbar HR, Abbas A, Ahmed M, Klodell CT Jr, Chang M, Dai Y, Draganov PV: The incidence, predictors and outcomes of gastrointestinal bleeding in patients with left ventricular assist device (LVAD). Dig Dis Sci. 2015, 60:3697-706. 10.1007/s10620-015-3743-4

48. Yavar Z, Cowger J, Moainie S, Salerno C, Ravichandran AK: Increased frequency of bleeding complications in females following LVAD implant. J Heart Lung Transplant. 2017, 36:S254. 10.1016/j.healun.2017.01.677 